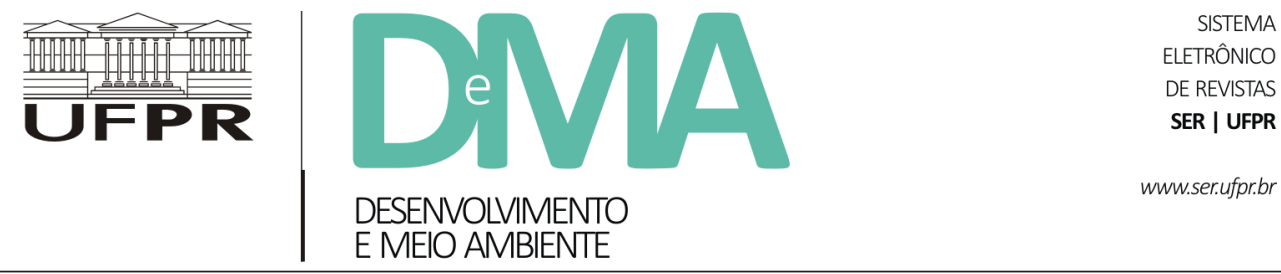

\title{
Subsídios para o planejamento estratégico costeiro do município de Jaguaruna, Santa Catarina
}

\section{Subsidies for the Coastal Planning of the Municipality of Jaguaruna, Santa Catarina}

Eduardo Marques MARTINS ${ }^{1 *}$, Nelson Luiz Sambaqui GRUBER ${ }^{2}$, Eduardo Guimarães BARBOZA², Samanta da Costa CRISTIANO ${ }^{1}$, Laura Dias PRESTES ${ }^{3}$, Rogério Portantiolo MANZOLLI ${ }^{4}$, Luana Carla PORTZ ${ }^{4}$, Gabriela Camboim ROCKETT ${ }^{5}$, Julio Fernandes de OLIVEIRA ${ }^{1}$, Rafael Mastracusa de OLIVEIRA ${ }^{1}$, Ricardo Augusto Lengler FRANCHINI ${ }^{1}$, Volney Junior Borges de BITENCOURT ${ }^{1}$, Túlio Pires WATANABE 6 , Renato Amabile LEAL ${ }^{1}$, Ricardo Burgo BRAGA ${ }^{7}$, José Luis Ballestrin FONTES ${ }^{8}$, Débora Sayuri Zanchi WATANABE ${ }^{1}$, Natália Zangirolymo VIANNA ${ }^{9}$, Bruna Fiscuk FERREIRA ${ }^{1}$, Marina Refatti FAGUNDES ${ }^{9}$, Mateus de Marques VILELLA ${ }^{9}$, Tayná ESTEVES ${ }^{10}$, Pâmela Cristina AZARIAS ${ }^{9}$

\footnotetext{
${ }^{1}$ Programa de Pós-Graduação em Geociências (PPGGEO), Universidade Federal do Rio Grande do Sul (UFRGS), Porto Alegre, RS, Brasil. ${ }^{2}$ Centro de Estudos de Geologia Costeira e Oceânica, Instituto de Geociências, Universidade Federal do Rio Grande do Sul (UFRGS), Porto Alegre, RS, Brasil.

${ }^{3}$ Programa de Pós-Graduação em Geografia (PPGG), Universidade Federal de Santa Catarina (UFSC), Florianópolis, SC, Brasil.

${ }^{4}$ Universidad de la Costa (CUC), Barranquilla, Colômbia.

${ }^{5}$ Prefeitura de São Leopoldo, RS, Brasil.

${ }^{6}$ Programa de Pós-Graduação em Geografia (PósGEA), Universidade Federal do Rio Grande do Sul (UFRGS), Porto Alegre, RS, Brasil.

${ }^{7}$ Pontifícia Universidade Católica do Rio Grande do Sul (PUC/RS), Porto Alegre, RS, Brasil.

${ }^{8}$ Associação de Balneários de Jaguaruna (ABJ), Jaguaruna, SC, Brasil.

${ }^{9}$ Universidade Federal do Rio Grande do Sul (UFRGS), Porto Alegre, RS, Brasil.

${ }^{10}$ Universidade Federal do Pampa (UNIPAMPA), Caçapava do Sul, RS, Brasil.

${ }^{*}$ E-mail de contato: geo.edum2@gmail.com
}

Artigo recebido em 29 de agosto de 2017, versão final aceita em 17 de novembro de 2017.

RESUMO: A ocupação sem planejamento da Zona Costeira tem promovido a substituição do ambiente natural original pelo ambiente antrópico, cuja implantação apresenta condições que desequilibram a Diversidade Ambiental (naturezas abiótica e biótica) e prejudicam o próprio ambiente antrópico. Essa problemática tende a continuar e se agravar em municípios pequenos, como é o caso de Jaguaruna/SC. O presente trabalho apresenta o método 
de estruturação das primeiras etapas de um planejamento estratégico costeiro desenvolvido no balneário Camacho/Jaguaruna por meio de ações e cenários de manejo baseados no mapeamento de condições de conflito, na aplicação do Î́ndice de Criticidade Legal-Ambiental (ICLA), no paradigma da Geodiversidade e na dinâmica sedimentar. Em ambiente de Sistema de Informações Geográficas, foi realizada a regionalização paisagística da Diversidade Ambiental pelo cruzamento de informações das naturezas abiótica e biótica. Após a identificação e a hierarquização das principais condições de conflitos pela aplicação do ICLA, cada condição de conflito com área superior a $1.000 \mathrm{~m} 2$ foi avaliada. Foram encontradas 71 condições de conflito, as quais abrangem 79,91\% das zonas ocupadas com atividades urbanas ou agrícolas. Ao confrontar os resultados com os instrumentos de gestão vigentes, as principais restrições observadas foram: desrespeito a condicionantes legais e ambientais de ocupação; saneamento básico deficiente; macrozoneamento e zoneamento urbano incoerentes com a dinâmica socioespacial do município; falta de investimento financeiro; e corpo técnico insuficiente. Os cenários de manejo permitiram projetar três tipos diferentes de intervenção (de médio prazo), que refletem distintas propostas de desenvolvimento, para deliberação e implementação por parte dos gestores públicos. A proposta metodológica, aliada à incorporação de diretrizes de outros instrumentos de gestão preexistentes, proporcionou: a identificação e a hierarquização de condições de conflito de forma simples e inteligível; a proposição de ações de manejo objetivas; a espacialização de cenários tendência e a continuidade de iniciativas de gestão preexistentes.

Palavras-chave: gerenciamento costeiro integrado; diversidade ambiental; sistemas de informações geográficas; ações e cenários de manejo.

ABSTRACT: The unplanned occupation of the Coastal Zone has promoted the replacement of the original natural environment by the anthropic environment. This transformation generates conditions that unbalance the Environmental Diversity (abiotic and biotic natures) and prejudice the anthropic environment. This problem tends to continue and worsen in small municipalities; as is the case of municipality of Jaguaruna, Santa Catarina, Brazil. The present paper presents the method of structuring the first steps of a coastal strategic plan developed in Camacho Balneary/Jaguaruna through actions and scenarios of management based on conflict conditions mapping, the application of the Legal - Environmental Criticality Index (ICLA, in Portuguese), the paradigm of Geodiversity and the local sedimentary dynamics. In a Geographic Information System environment, the regionalization of the Environmental Diversity landscape was carried out by "map algebra" of abiotic and biotic information. After identifying and ranking the main conflict conditions by applying the ICLA, each conflict condition with an area over $1,000 \mathrm{~m} 2$ was evaluated. There were 71 conflict conditions, which cover $79.91 \%$ of the areas occupied with urban or agricultural activities. When comparing the results with the current management instruments, the main restrictions observed were: disrespect for legal and environmental constraints of occupation; poor sanitation; territory and urban zoning incoherent with the socio-spatial dynamics of Jaguaruna; lack of financial investment; and insufficient technical staff. The management scenarios allowed the design of three different types of intervention (medium term), which reflect different development proposals, for deliberation and implementation by public managers. The methodological proposal, combined with the incorporation of pre-existing management initiatives and plans, provided: the identification and hierarchy of conflict conditions in a simple and intelligible way; the proposition of objective management actions; the spatialization of trend scenarios and the continuity of pre-existing management initiatives.

Keywords: integrated coastal zone management; environmental diversity; geographic information system; actions and scenarios of management. 


\section{Introdução}

A Área de Proteção Ambiental (APA) da Baleia Franca é uma unidade de conservação com $1.600 \mathrm{~km}^{2}$ que abrange regiões continentais e marinhas. Localizada no Sul do Estado de Santa Catarina/Brasil, se estende por dez municípios, entre os quais, Jaguaruna. Com um pouco mais de 17.000 habitantes, Jaguaruna é classificado pelo Instituto Brasileiro de Geografia e Estatística (IBGE) como município de Pequeno Porte I ( $<20.000$ hab.). Segundo dados econômicos coletados pelo IBGE, em 2014 o Produto Interno Bruto (PIB) per capita do município alcançou um pouco mais de $\mathrm{R} \$ 19.200$; em relação ao Valor Adicionado Bruto, o setor de serviços correspondeu com $58 \%$ de toda a riqueza gerada no município, seguido pelos setores primário e secundário, com 22 e $20 \%$, respectivamente.

Devido à intensificação de conflitos de uso da terra relacionados à ocupação de Áreas de Preservação Permanente (APP) nos balneários costeiros de Jaguaruna, em 2011 o Ministério Público Federal Brasileiro (MPF) decretou um embargo a empreendimentos infraestruturais nos balneários do município. Aárea embargada abrange uma faixa longitudinal adjacente ao mar de $38 \times 1,5 \mathrm{~km}$ (ou $57 \mathrm{~km}^{2}$ ), denominada neste trabalho como "Faixa Litorânea".

A problemática em questão está relacionada: (a) à falta de planejamento adequado e às limitadas capacidades de (b) ação dos gestores públicos (corpo técnico e disponibilidade de equipamentos) e (c) de investimento financeiro, com vistas ao equacionamento dos impactos ambientais oriundos da expansão urbana acelerada, normalmente, para fins de "segunda residência" (segundo dados do Censo
Populacional de 2010, coletados pelo IBGE, 62,3\% dos domicílios são ocupados de forma intermitente).

Os principais conflitos observados são: (a) ocupação de ambientes protegidos por lei e por outras normativas (como APPs); (b) substituição e modificação de hábitats naturais; (c) deterioração de sítios arqueológico-históricos (o maior sambaqui da região é utilizado em trilhas off-road); (d) alteração na paisagem devido a modificações em processos morfodinâmicos (construção e manutenção artificial de canal de comunicação entre a lagoa do Camacho e o oceano, que se interpõe de forma perpendicular ao sentido de migração das dunas, NE - SW); (e) elevação dos níveis de poluição pelo sistema de saneamento básico deficiente (relacionado ao lançamento de efluentes líquidos não tratados e à deposição de resíduos sólidos no solo e nos cursos fluviais e corpos d'água); e (f) dispersão sem controle de espécies arbóreas exóticas/invasoras.

Ao longo dos últimos quatro anos, foram promovidas ações e propostas com vistas à resolução dos problemas supracitados (recorrentes em todo o Litoral Sul de Santa Catarina), sintetizadas a seguir: diagnósticos socioeconômico e ambiental da Faixa Litorânea de Jaguaruna (Gruber et al., 2017a, 2017b) referentes à primeira etapa do projeto intitulado Diagnóstico e Plano de Manejo das Dunas Frontais do Município de Jaguaruna, desenvolvido por pesquisadores do Centro de Estudos em Geologia Costeira e Oceânica da Universidade Federal do Rio Grande do Sul; reuniões e oficinas na Secretaria de Desenvolvimento Sustentável do Estado de Santa Catarina (SDS/SC) entre o Comitê Gestor Integrado para o Planejamento Territorial da Região Costeira de Santa Catarina (GERCO/SC), representantes de órgãos municipais, estaduais e federais, sociedade civil organizada, membros de 
universidades e demais atores sociais interessados, que culminaram na elaboração e entrega ao MPF do documento denominado Roteiro Metodológico (Santa Catarina, 2015), idealizado como uma proposta metodológica para avaliação da situação específica de balneários com vistas à elaboração de Termos de Ajuste de Conduta (TACs). Mas o MPF considerou as proposições contidas no Roteiro Metodológico de difícil implementação e acompanhamento pela subjetividade e pela falta de critérios objetivos de algumas ações.

O objetivo do presente trabalho é apresentar a proposta de Gerenciamento Costeiro Integrado (GCI), elaborada para estruturar as primeiras etapas do planejamento estratégico costeiro (definição de metas e métodos) para a Faixa Litorânea do município de Jaguaruna e subsidiar o MPF na definição de TACs, baseada em cenários de manejo elaborados a partir do mapeamento e avaliação de condições de conflito, da aplicação do Índice de Criticidade Legal-Ambiental (ICLA) (Gruber et al., 2017c), da análise integrada da Diversidade Ambiental (naturezas abiótica e biótica), do paradigma da Geodiversidade (Gray, 2013), da dinâmica sedimentar e das diretrizes de instrumentos de gestão e de planejamento preexistentes.

Para avaliação, detalhamento e aprimoramento da proposta, foi selecionada como área piloto o balneário Camacho, no município de Jaguaruna (Figura 1), seleção motivada pela maior complexidade das

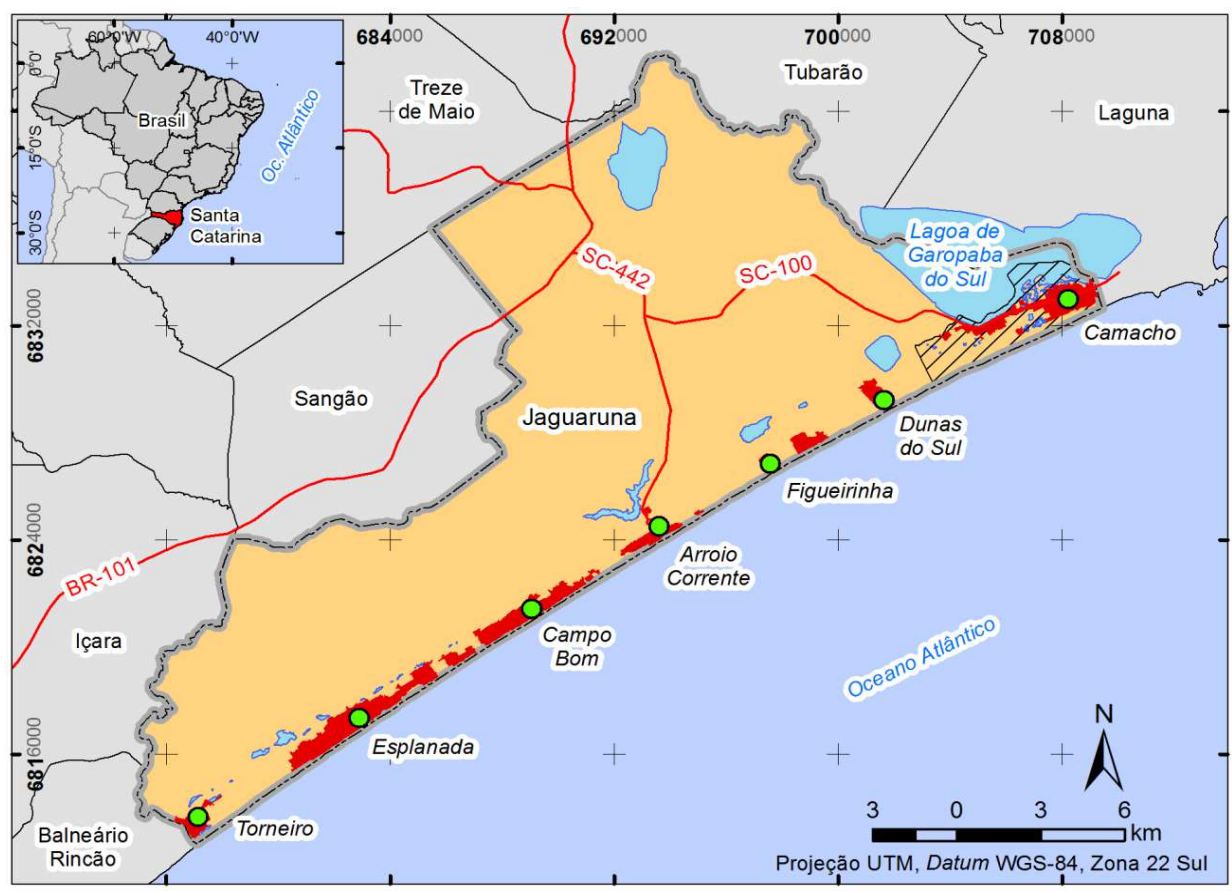

FIGURA 1 - Localização da área de estudo no município de Jaguaruna (área hachurada em preto, ao NE): o balneário Camacho, faixa com extensões perpendicular média e longitudinal de 1,5 e $6,5 \mathrm{~km}$, respectivamente $\left(12,5 \mathrm{~km}^{2}\right)$. Destacam-se as principais áreas urbanizadas, localidades, vias de acesso e corpos d'água.

FONTE: IBGE; elaboração própria. 
condições de conflito de uso da terra e da dinâmica costeira observadas nesse balneário (em relação a toda a Faixa Litorânea de Jaguaruna).

\section{Metodologia}

Todos os procedimentos de análise ambiental e espacial foram realizados em ambiente de Sistema de Informações Geográficas (SIG), com o uso de dados georreferenciados organizados em um banco de dados geográfico. A identificação dos diferentes objetos geográficos está diretamente relacionada com a capacidade de representar a compreensão dos conflitos, por isso deve ser percebida por meio da conjuntura dos conflitos locais. A escala de análise adotada para a avaliação da área de estudo foi 1:10.000, considerada adequada para a avaliação dos fenômenos.

\subsection{Regionalização das paisagens}

A regionalização foi realizada a partir da obtenção das seguintes informações: (i) mapeamento da geodiversidade local e ocorrência de sambaquis; (ii) espacialização da dinâmica abiótica costeira; (iii) mapeamento da cobertura vegetal e do uso da terra; e (iv) mapeamento de condições urbanas.

\subsubsection{Mapeamento da geodiversidade e ocorrência de sambaquis}

Por meio de uma analogia, pode-se dizer que a geodiversidade refere-se à diversidade abiótica do planeta, tal qual a biodiversidade abrange a diversidade biótica da Terra. Ambas as naturezas conformam a Diversidade Ambiental da Terra. A geodiversidade é compreendida como "a diversidade natural da Geologia (rochas, minerais, fósseis), da Geomorfologia (relevo, topografia, processos físicos), dos solos e das feições hidrológicas, incluídas as suas organizações, estruturas, sistemas e contribuições à paisagem" (Gray, 2013, p. 26).

Os sambaquis são "sítios arqueológicos monticulares distribuídos por toda a costa brasileira [...] comumente formados por camadas de conchas mais ou menos espessas intercaladas por numerosos estratos finos e escuros, ricos em materiais orgânicos [...] tradicionalmente [interpretados] como vestígios de acampamentos sucessivos de bandos de coletores de moluscos e pescadores" (DeBlasis et al., 2007, p. 1);

TABELA 1 - Planos de informação utilizados para mapear a geodiversidade local

\begin{tabular}{|c|c|c|}
\hline Informação & Escala & Fonte \\
\hline Geologia & $1: 100.000$ & Horn Filho et al. (2012) \\
\hline Geomorfologia & Compatível com a escala de análise & Interpretação de imagens e aferição em campo \\
\hline Recursos hídricos & Compatível com a escala de análise & Interpretação de imagens e aferição em campo \\
\hline Topografia & $\begin{array}{l}\text { Compatível com a escala de análise (resolução } \\
\text { espacial da imagem: } 40 \mathrm{~cm} \text { ) }\end{array}$ & $\begin{array}{l}\text { Modelo Numérico de Superfície (MNS) (San- } \\
\text { ta Catarina, 2012a) }\end{array}$ \\
\hline Sambaquis & Compatível com a escala de análise & Interpretação de imagens e aferição em campo \\
\hline
\end{tabular}

FONTE: Elaboração própria. 
não obstante, vêm sendo considerados como estruturas intencionalmente construídas (Gaspar \& DeBlasis, 1992 apud DeBlasis et al., 2007). Foram considerados neste sub-subcapítulo exclusivamente pela natureza abiótica de seus constituintes.

Os dados da natureza abiótica foram obtidos de mapeamentos prévios e de levantamento com aferição em campo (Tabela 1). Na medida do possível, foram implementados aprimoramentos e atualizações nas informações; nos demais casos, manteve-se a integridade da informação. As informações sobre o clima não foram utilizadas por não serem representativas devido à escala geográfica.

Após o cruzamento dessas informações por rotina análoga à álgebra de mapas e avaliação do resultado, obtiveram-se 10 classes temáticas que representam condições homogêneas de ocorrência de fenômenos físicos da geodiversidade local, a saber: (1) Campo de dunas móveis de cadeias barcanoides; (2) Campo de dunas móveis de cadeias barcanoides com lençol freático aflorante; (3) Lençol de areia; (4) Lençol de areia com lençol freático aflorante; (5) Campo de dunas semifixas com lençol freático aflorante; (6) Campo de dunas barcanas móveis; (7) Planície lagunar; (8) Face de praia - antepraia; (9) Sambaqui; e (10) cursos e corpos d'água.

\subsubsection{Espacialização de dinâmica abiótica costeira}

Foram obtidas informações sobre:

- Taxa anual de deslocamento do campo de dunas: $120 \mathrm{~m}$ de acordo com o vento predominante (sentido NE - SW) (em projeção de 20 anos), a partir de análise temporal de dunas e de cristas de dunas em fotografias aéreas georreferenciadas dos anos de 1938, 1957 e 1978 (Santa Catarina, 1938; 1957; 1978), de ortofotocartas de 2002 (IBGE, 2002a; 2002b; 2002c; 2002d) e de ortofotomosaico de 2012 (Santa Catarina, 2012b) da área de estudo; Taxa de deslocamento e comportamento da linha de costa: deslocamento de $8 \mathrm{~m}$ no sentido oceano-continente (em projeção de 20 anos), a partir de análise temporal das fotografias aéreas georreferenciadas, das ortofotocartas e do ortofotomosaico supracitados. O comportamento observado também foi identificado em subsuperfície por meio de levantamentos de georradar (Martins et al., 2014), os quais evidenciaram o comportamento retrogradacional de longo período na área de estudo pela inclinação dos refletores no sentido oceano-continente;

- Localização de áreas alagáveis: a partir de mapeamento prévio do plano diretor municipal (PDM) (Jaguaruna, 2014), classificação supervisionada e fotointerpretação em ortofotomosaico de 2012;

- Localização de áreas com risco de inundação marinha: foram selecionadas as áreas à jusante da curva de nível de dois metros. Essa avaliação foi realizada ao sobrepor imagem georreferenciada de alta resolução do software Google $^{T M}$ Earth Pro do dia seguinte a um evento climático extremo, com registro de inundação marinha na área de estudo (Vieira, 2016; Folha Regional, 2016) e o MNS da área de estudo. Foi observado que a área inundada e grande parte da "areia molhada" (sobrelavagem) ficaram à jusante da curva de nível de dois metros. 


\subsubsection{Mapeamento da cobertura vegetal e do uso da terra}

Gruber et al. (2017c) elaboraram mapeamento do uso da terra a partir de classificação supervisionada do ortofotomosaico de 2012 e da aferição de classes temáticas em campo para posterior edição de talhões classificados de forma errônea. O mapeamento vegetacional foi aprimorado segundo a identificação em campo da vegetação predominante e de espécies características de restinga (CONAMA, 1999) e reclassificado como vegetação de restinga herbácea/subarbustiva (menos de $1 \mathrm{~m}$ de altura), arbustiva (até $5 \mathrm{~m}$ de altura) ou arbórea (mais de 5 $m$ de altura).

\subsubsection{Mapeamento de condições urbanas}

Para o mapeamento das condições urbanas (socioeconômicas e infraestruturais), foram utilizados dados do censo populacional de 2010 realizado pelo IBGE, a saber: número total de domicílios e os percentuais de ocorrência de domicílios permanentes, abastecimento água por rede geral, esgotamento sanitário por rede geral, coleta de resíduos sólidos e distribuição de energia elétrica. Ademais, foram mapeados no software Google ${ }^{T M}$ Earth Pro, com o uso da ferramenta Street View, o tipo de pavimentação de vias e calçadas (relativo à permeabilidade) e a ocorrência de infraestrutura de escoamento pluvial; essas informações foram avaliadas em saídas de campo para corrigir possíveis desatualizações das características de pavimentação observadas no software utilizado.

Todos esses dados foram agrupados por setor censitário; ressalta-se que a informação sobre as vias e o calçamento foi ponderada segundo o percentual da extensão longitudinal impermeável em relação à extensão longitudinal total. As manchas urbanas abrangidas nos setores censitários foram classificadas em baixa, média e alta densidade de ocupação, segundo o número de domicílios permanentes e condições urbanas semelhantes.

\subsubsection{Cruzamento das informações da diver- sidade ambiental}

Obtidos todos os planos de informação sobre as naturezas abiótica e biótica, essas informações foram cruzadas em rotina computacional análoga à álgebra de mapas para a obtenção de 70 classes temáticas, as quais foram avaliadas e generalizadas. Obtiveram-se 13 regiões paisagísticas da Diversidade Ambiental da área de estudo, a saber: (1) Cursos e corpos d'água; (2) Sambaquis; (3) Face de praia; (4) Campo de dunas móveis com risco de alagamento; (5) Campo de dunas móveis com risco de inundação; (6) Campo de dunas semifixas com risco de alagamento; (7) Vegetação de restinga herbácea-subarbustiva com risco de alagamento; (8) Vegetação de restinga arbustiva-arbórea; (9) Vegetação de restinga indiscriminada, com ocorrência generalizada de espécies exóticas; (10) Ocupação com característica rural predominante, com risco de alagamento; (11) Ocupação com característica urbana de média densidade; (12) Ocupação com característica urbana de baixa densidade; e (13) Ocupação com característica urbana de baixa densidade com risco de alagamento ou inundação. 


\subsection{Identificação de conflitos e condicionantes}

Foram considerados conflitos/condicionantes aquelas práticas e/ou atividades e/ou condições de uso da terra e organização territorial que: (a) estão em discordância com a legislação e normativas vigentes e/ou com os instrumentos e planos de gestão; (b) põem em risco a manutenção da dinâmica e dos processos sedimentares costeiros e, inclusive, da ocupação e da manutenção das atividades antrópicas.

Os conflitos/condicionantes identificados foram dos seguintes tipos: (a) pontual difuso - podem variar no tempo e no espaço (como locais de disposição informal de resíduos sólidos); (b) pontual restrito - a variação no espaço é relativamente baixa ou inexistente (como ocupações irregulares); (c) área - inconsistência entre o uso da terra e as características físicas e/ou biológicas; (d) territorial - incoerência entre o uso da terra e as determinações legais e normativas.

Os conflitos pontuais foram organizados nas seguintes categorias: (a) vias/acessos; (b) ocupação irregular/inapropriada; (c) depósito irregular de resíduos sólidos; (d) ocorrência de espécies exóti- cas; (e) múltiplos (múltipla ocorrência de conflitos das outras categorias); e (f) outros. Os conflitos da categoria "área" foram mapeados a partir de dados e informações secundárias (quando existentes), identificação in loco, por subsídios de sensoriamento remoto e/ou de levantamento fotográfico aéreo (Tabela 2); os conflitos territoriais derivam da espacialização em ambiente de SIG de medidas espaciais contidas em leis e normativas, e no Roteiro Metodológico (Tabela 3).

Os conflitos foram organizados por lógica binária a partir da soma de conflitos por unidade de área (ocorrência, "1"; inexistência, "0") e codificados como mostra o exemplo contido na Tabela 4, em que são apresentadas as tabulações para as condições de conflito com somente um conflito e com sobreposição de cinco e seis conflitos.

\subsection{Aplicação do ICLA}

A identificação dos principais conflitos e condicionantes ocorreu em saídas de campo e subsidiou a aplicação do Índice de Criticidade Legal-Ambiental (ICLA) e a elaboração das ações e dos cenários de manejo. O ICLA pode ser definido como a condição de adequação dos pontos de vista

TABELA 2 - Limites/Áreas espacializado(a)s para a avaliação de conflitos de área

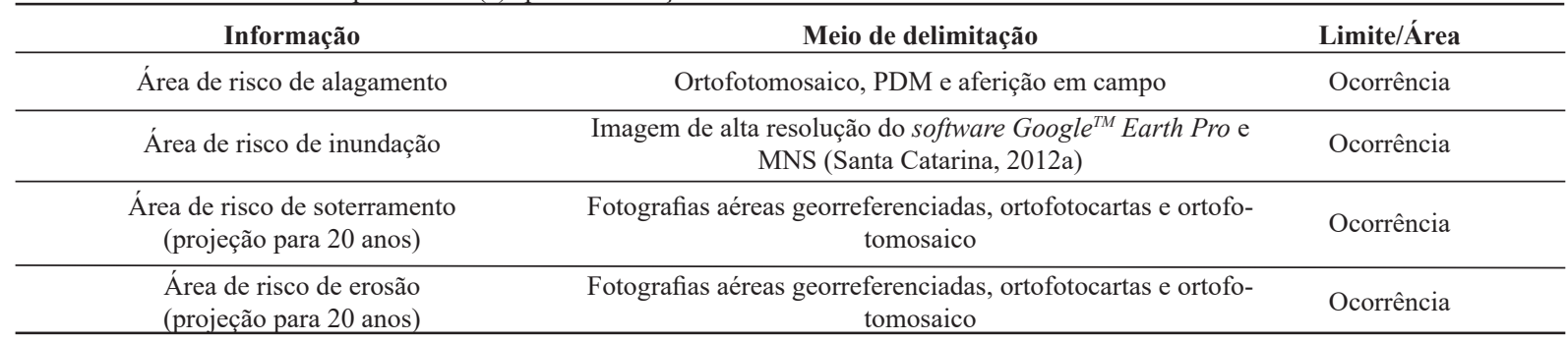

FONTE: elaboração própria 
TABELA 3 - Limites/Áreas espacializado(a)s para a avaliação de conflitos territoriais

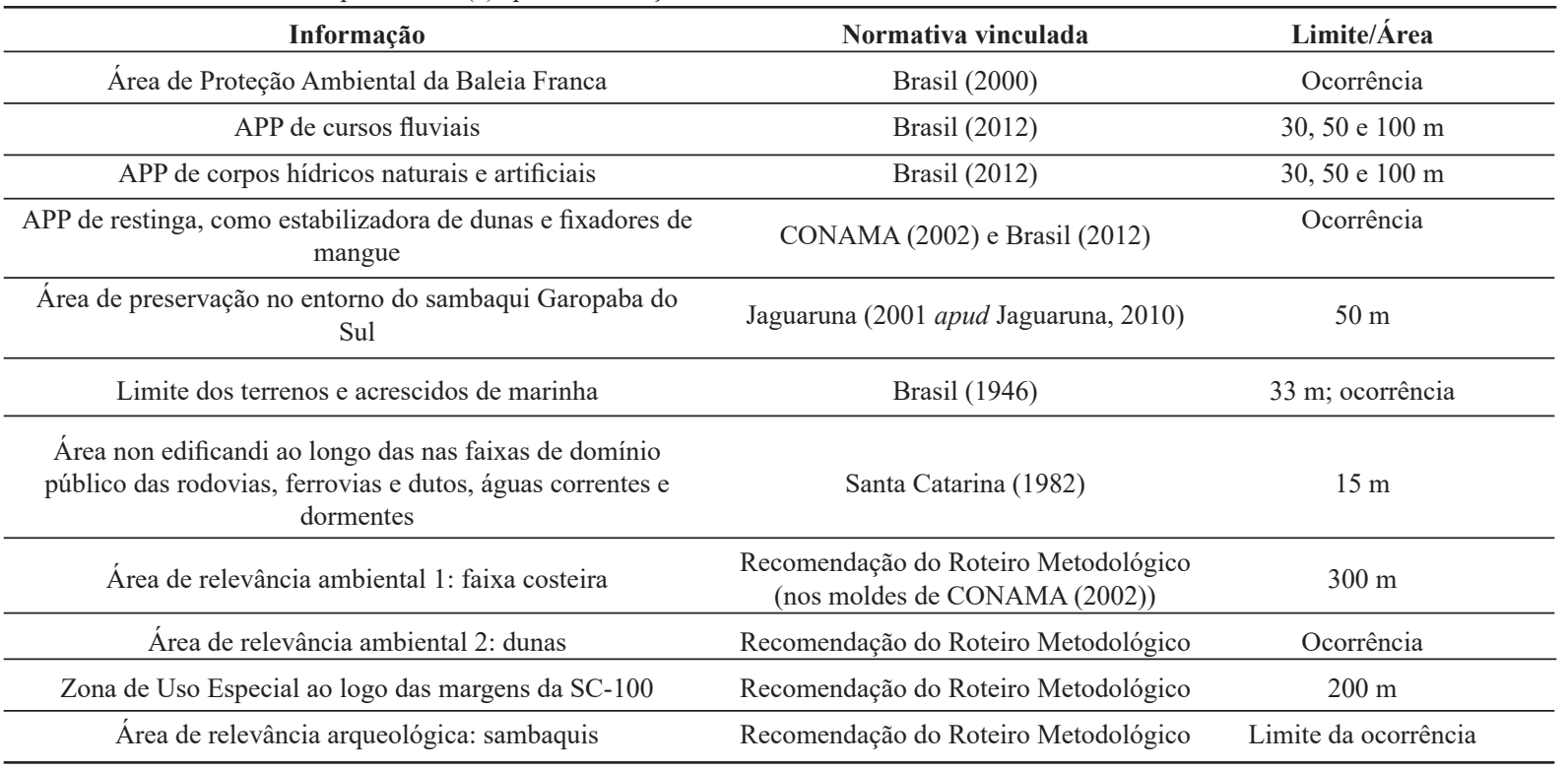

FONTE: elaboração própria.

legal e ambiental da ocupação antrópica em relação aos desígnios normativos relacionados à proteção ambiental, aos fenômenos naturais locais, ao parcelamento do solo e ao ordenamento territorial, e tem por objetivo auxiliar o processo decisório no que tange à priorização de ações e de medidas que almejem equacionar e/ou mitigar condições de conflito (Gruber et al., 2017c). Fundamenta-se na aplicação de rotinas de geoprocessamento análogas à álgebra de mapas em ambiente de SIG nas seguintes categorias de informação:

- Base Ambiental: (a) identificação de objetos geográficos ou parâmetros ambientais relevantes (como feições geológicas e geomorfológicas, e formações vegetais); e (b) espacialização de dinâmicas ambientais que possam causar risco à integridade física de pessoas e infraestruturas (como áreas de risco à inundação ou ao deslocamento de massa/gravitacional, vetores de direção de migração de campos de dunas, avulsão de canais fluviais, erosão costeira etc.);

- Base Legal: espacialização de limites e áreas de abrangência relacionadas (a) aos bens da União e ao parcelamento do solo e/ou uso e ocupação do solo expressas em normativas pertinentes; e (b) à conservação/preservação ambiental expressas em normativas pertinentes, nesse caso, à zona costeira.

O resultado final mostra o acúmulo de conflitos por unidade de área (Tabela 5).

As Bases Ambiental e Legal constam no Quadro 2 e no Quadro 3, respectivamente. Para que os conflitos pontuais também fizessem parte da avaliação do ICLA, aplicou-se um buffer de $100 \mathrm{~m}$ para denotar a ocorrência das categorias supracitadas (Tabela 4). 
TABELA 4 - Exemplo da organização binária e da codificação das condições de conflito no Balneário Camacho somente para os casos em que foram observados um conflito e sobreposição de cinco e seis conflitos (ocorrência, "1"; inexistência, "0")

\begin{tabular}{|c|c|c|c|c|c|c|c|c|c|c|c|c|c|c|}
\hline $\begin{array}{c}\text { Soma- } \\
\text { tório de } \\
\text { conflitos } \\
\text { por } \\
\text { unidade } \\
\text { de área } \\
\text { (ICLA) }\end{array}$ & $\begin{array}{l}\text { Código } \\
\text { da } \\
\text { condi- } \\
\text { ção de } \\
\text { conflito }\end{array}$ & $\begin{array}{c}\text { Risco de } \\
\text { inunda- } \\
\text { ção (1) } \\
\text { ou ala- } \\
\text { gamento } \\
\text { (2) }\end{array}$ & $\begin{array}{c}\text { Erosão } \\
\text { costei- } \\
\text { ra }\end{array}$ & $\begin{array}{c}\text { Terre- } \\
\text { nos e } \\
\text { acres- } \\
\text { cidos } \\
\text { de } \\
\text { mari- } \\
\text { nha }\end{array}$ & $\begin{array}{c}\text { APP } \\
\text { de re- } \\
\text { cursos } \\
\text { hídri- } \\
\text { cos }\end{array}$ & $\begin{array}{c}\text { APP } \\
\text { res- } \\
\text { tinga } \\
\text { fixado- } \\
\text { ra de } \\
\text { dunas }\end{array}$ & $\begin{array}{c}\text { Áreas } \\
\text { non } \\
\text { aedifi- } \\
\text { candi }\end{array}$ & 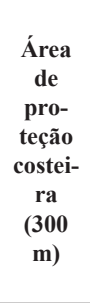 & $\begin{array}{l}\text { Área } \\
\text { de } \\
\text { prote- } \\
\text { ção de } \\
\text { dunas }\end{array}$ & $\begin{array}{c}\text { Área } \\
\text { de } \\
\text { prote- } \\
\text { ção do } \\
\text { sam- } \\
\text { baqui } \\
\text { Garo- } \\
\text { paba } \\
\text { do Sul } \\
(\mathbf{5 0} \mathrm{m})\end{array}$ & $\begin{array}{l}\text { Área } \\
\text { de } \\
\text { prote- } \\
\text { ção de } \\
\text { samba- } \\
\text { quis }\end{array}$ & $\begin{array}{c}\text { Zona } \\
\text { de Uso } \\
\text { Espe- } \\
\text { cial ao } \\
\text { longo } \\
\text { da } \\
\text { SC-100 } \\
(200 n \\
\text { m) }\end{array}$ & 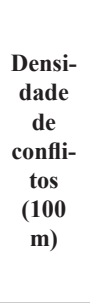 & $\begin{array}{c}\text { Soter- } \\
\text { ramen- } \\
\text { to }\end{array}$ \\
\hline 0 & 0 & 0 & 0 & 0 & 0 & 0 & 0 & 0 & 0 & 0 & 0 & 0 & 0 & 0 \\
\hline 1 & 101 & 0 & 0 & 0 & 0 & 0 & 0 & 0 & 0 & 0 & 0 & 0 & 0 & 1 \\
\hline 1 & 102 & 0 & 0 & 0 & 0 & 0 & 0 & 0 & 0 & 0 & 0 & 0 & 1 & 0 \\
\hline 1 & 103 & 0 & 0 & 0 & 0 & 0 & 0 & 0 & 0 & 0 & 0 & 1 & 0 & 0 \\
\hline 1 & 106 & 0 & 0 & 0 & 0 & 0 & 0 & 1 & 0 & 0 & 0 & 0 & 0 & 0 \\
\hline 1 & 107 & 0 & 0 & 0 & 0 & 0 & 1 & 0 & 0 & 0 & 0 & 0 & 0 & 0 \\
\hline 1 & 108 & 0 & 0 & 0 & 1 & 0 & 0 & 0 & 0 & 0 & 0 & 0 & 0 & 0 \\
\hline 1 & 109 & 0 & 0 & 1 & 0 & 0 & 0 & 0 & 0 & 0 & 0 & 0 & 0 & 0 \\
\hline 1 & 110 & 1 & 0 & 0 & 0 & 0 & 0 & 0 & 0 & 0 & 0 & 0 & 0 & 0 \\
\hline 1 & 110 & 2 & 0 & 0 & 0 & 0 & 0 & 0 & 0 & 0 & 0 & 0 & 0 & 0 \\
\hline 1 & 111 & 0 & 1 & 0 & 0 & 0 & 0 & 0 & 0 & 0 & 0 & 0 & 0 & 0 \\
\hline 5 & 501 & 1 & 0 & 0 & 1 & 0 & 0 & 1 & 1 & 0 & 0 & 0 & 1 & 0 \\
\hline
\end{tabular}

FONTE: elaboração própria. 
TABELA 5 - Classificação do ICLA em classes de criticidade a partir do acúmulo de conflitos por unidade de área

\begin{tabular}{lll}
\hline Número de conflitos por unidade de área & Classe de criticidade & Representação gráfica \\
\hline 0 & Inexistente & Transparente \\
1 & Baixo \\
$2-3$ & Moderado \\
$4-5$ & Elevado \\
$>6$ & Complexo & \\
\hline
\end{tabular}

FONTE: elaboração própria.

\subsection{Elaboração das ações e dos cenários de manejo}

Uma avaliação conjunta do ICLA e das condições de conflito em relação à regionalização das paisagens foi realizada com o intuito de obter uma caracterização integrada das condições de vulnerabilidade de cada região (vinculada à dinâmica sedimentar). Posteriormente, cada região é segmentada de acordo com a abrangência: do perímetro urbano, da zona de expansão urbana (áreas não ocupadas dentro do perímetro urbano), das zonas ocupadas (fora do perímetro urbano) e da Macrozona Agrícola (proposta pelo PDM).

Todas as regiões maiores que $1.000 \mathrm{~m}^{2}$ foram avaliadas; as demais regiões foram incorporadas a regiões semelhantes contíguas $\left(<100 \mathrm{~m}^{2}\right)$ ou serviram somente como indicadores $(100-1.000$ $\mathrm{m}^{2}$ ). A avaliação incorpora as diretrizes do PDM, do Roteiro Metodológico e dos preceitos de uma APA (a APA da Baleia Franca ainda não conta com plano de manejo) na análise da vulnerabilidade de cada região, a qual subsidia a elaboração das ações de manejo fundamentadas nas propostas de cenários de manejo, projetados a partir de três tipos de intervenções/concepções:
- Cenário I - Manutenção da tendência atual: manutenção das tendências atuais de uso da terra e de ordenamento territorial;

- Cenário II - Sustentabilidade como meta: readequação parcial da tendência atual, a qual consiste em:

Reordenamento do território de acordo com as diretrizes de planos de gestão instituídos pelos poderes municipal, estadual e federal em conformidade com legislações e normativas vigentes, e as vulnerabilidades observadas;

Adequação das formas de uso da terra e da infraestrutura urbana;

Implementação de práticas de conservação ambiental (promoção do desenvolvimento sustentável e manutenção do status quo);

- Cenário III - Reconstituição ambiental: readequação abrangente da tendência atual, a qual consiste em:

Reinterpretações do espaço geográfico em relação à Diversidade Ambiental, com o objetivo de adequar as formas de apropriação do território e da infraestrutura urbana instalada e planejada de acordo com as vulnerabilidades e potencialidades do ambiente físico; 
Instituição de política pública municipal de ordenamento territorial que (a) adéque os planos e instrumentos de gestão, assim como a legislação e normativas municipais vigentes, às condições de vulnerabilidade observadas; e (b) fomente práticas e atividades que usufruam das potencialidades do ambiente físico; e,

Implementação de práticas de preservação ambiental (restauração, operação e ocorrência de processos e dinâmicas naturais originais).

Dessa forma, por meio da compreensão das vulnerabilidades de cada região (vinculadas à dinâmica sedimentar) e da integração de instrumentos de gestão preexistentes, o método propõe ações de manejo objetivas relacionadas aos cenários, como mostra a Figura 2.

\subsection{Avaliação da geodiversidade}

A base estrutural do paradigma da Geodiversidade nas Geociências fundamenta-se na a tríade
"Geodiversidade - Geopatrimônio - Geoconservação", em que: "a Geodiversidade é a qualidade que se procura conservar, a Geoconservação é o processo envolvido na tentativa de conservá-la e o Geopatrimônio compreende os exemplares representativos de feições e processos aos quais dirigimos esforços de gestão para conservá-lo" (Sharples, 2002, p. 57).

A geodiversidade pode ser acessada pela avaliação de seus valores intrínseco (ou de existência), educacional e científico, e de seus serviços ecossistêmicos abióticos de regulação, de suporte, de provisão e culturais - ou "geosserviços", em analogia à proposição de MEA (2003). Na área de estudo, foi aplicado o método denominado de "monetarização análoga", o qual consiste na elaboração de uma analogia entre o valor cobrado por determinados serviços e produtos e o suposto "valor monetário" que os benefícios gerados pelos geosserviços teriam caso fossem oferecidos como um serviço ou produto.

O intuito dessa abordagem é valorar os benefícios que os geosserviços proporcionam ao homem e

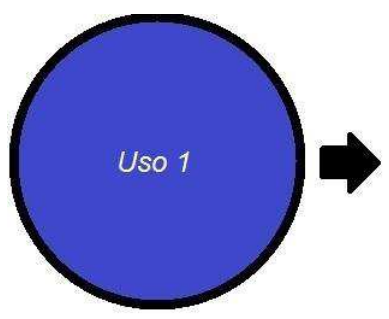

Situação I

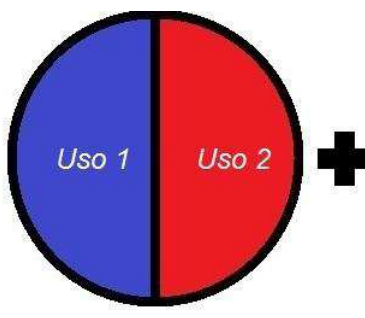

Situação II

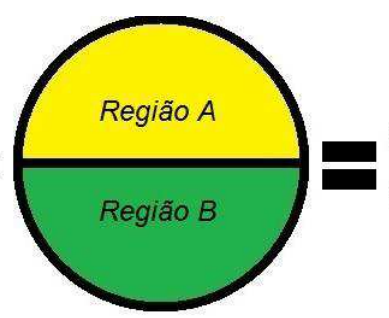

Regionalização

Diversidade

Ambiental

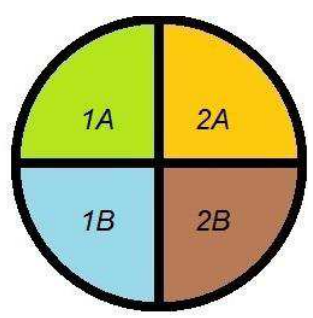

Ações de Manejo Diferenciadas

FIGURA 2 - Síntese da proposta que fundamenta a elaboração dos cenários de manejo: a partir de uma determinada condição (Situação I), projeta-se um cenário futuro (Situação II) e, em conformidade com a regionalização, ações de manejo diferenciadas são propostas para propiciar o avanço rumo à condição futura almejada (Situação II).

FONTE: elaboração própria. 
potencializar a compreensão de sua relevância para a sociedade por meio de "valores pecuniários". Os geosserviços avaliados e os serviços e/ou produtos utilizados para a aplicação do método proposto constam na Tabela 6 .

Fazem-se as seguintes ressalvas: (a) não foram avaliados os custos relacionados à replica ou à substituição de geosserviços de forma artificial em escala semelhante à natural, e possíveis reconstruções e recuperações de infraestruturas antrópicas; (b) pelo intuito pedagógico do método, nem todos os geosserviços, assim como as suas inter-relações, são passíveis de serem avaliados devido à complexidade da natureza (como tentar valorar os ciclos biogeoquímicos, por exemplo); e (c) optou-se por subestimar valores e condições haja vista que os valores dos serviços e/ou dos produtos utilizados para a realização da comparação podem variar segundo o local de referência e o período temporal de pesquisa.

\section{Resultados e discussões}

Dos 91 tipos de condição de conflito possíveis, foram encontrados 71 na área de estudo, os quais abrangem $63,53 \%$ da área do balneário; ao avaliar somente as zonas ocupadas (com atividades urbanas ou agrícolas), 79,91\% apresentam algum tipo de condição de conflito. Não obstante, na grande maioria dos casos a condição de conflito é considerada baixa ou moderada (Figura 3). Ao confrontar as condições de conflito com as diretrizes e princípios supracitados, os principais problemas observados foram: (a) âmbito ambiental - condicionantes relacionadas ao risco de alagamento e conflitos de ocupação de APPs ou de áreas vulneráveis; (b) âmbito social - "grilagem" e falta de saneamento básico adequado; (c) âmbito gerencial - o PDM apresenta inconsistências que impedem a consecução adequada de suas propostas, e carência de recursos financeiros e humanos para monitorar, controlar, fiscalizar e avaliar atividades; e (d) âmbito territorial - macrozoneamento e zoneamento urbano incoerentes com a dinâmica socioespacial do município e falta de regulamentação adequada em nível municipal sobre a "Transferência do Direito de Construir” (Brasil, 2001).

Em relação à valoração dos geosserviços, obtiveram-se os seguintes resultados:

TABELA 6 - Geosserviços avaliados e os serviços e/ou produtos utilizados para a aplicação do método de monetarização análoga na área de interesse

\begin{tabular}{lccc}
\hline & Geosserviço & Categoria & Serviço ou produto análogo \\
\hline 1 & Controle de inundação marinha & Regulação & Segurança patrimonial privada (anual) \\
\cline { 1 - 1 } 2 & Recarga/Filtragem de aquífero & Suporte & Custo unitário da vela de filtro de barro \\
\hline 3 & Provisão de hábitat & Valor médio do Imposto Predial e Territorial Urbano \\
(IPTU) de Jaguaruna
\end{tabular}

FONTE: elaboração própria 
- Controle de Inundação: como serviço análogo foi utilizado o serviço de segurança patrimonial privada, o qual consiste de monitoramento com câmeras e/ou alarmes $24 \mathrm{~h}$ e um ronda noturna, com custo mensal entre R \$100 - 280; optou-se por um valor intermediário $(\mathrm{R} \$ 150$ / mês ou R \$ 1.800/ano). Com uma média de no- ve lotes por quadra (de $115 \mathrm{~m}$, quadra mais via de acesso, e em frente à praia), em 6,50 km de extensão de área ocupada haveria 504 pagantes pelo geosserviço, ou seja, R \$ 907.200/ano;

- Recarga/Filtragem de água: os campos de dunas são filtradores e armazenadores naturais de água. $\mathrm{Na}$ área de interesse, o campo de dunas

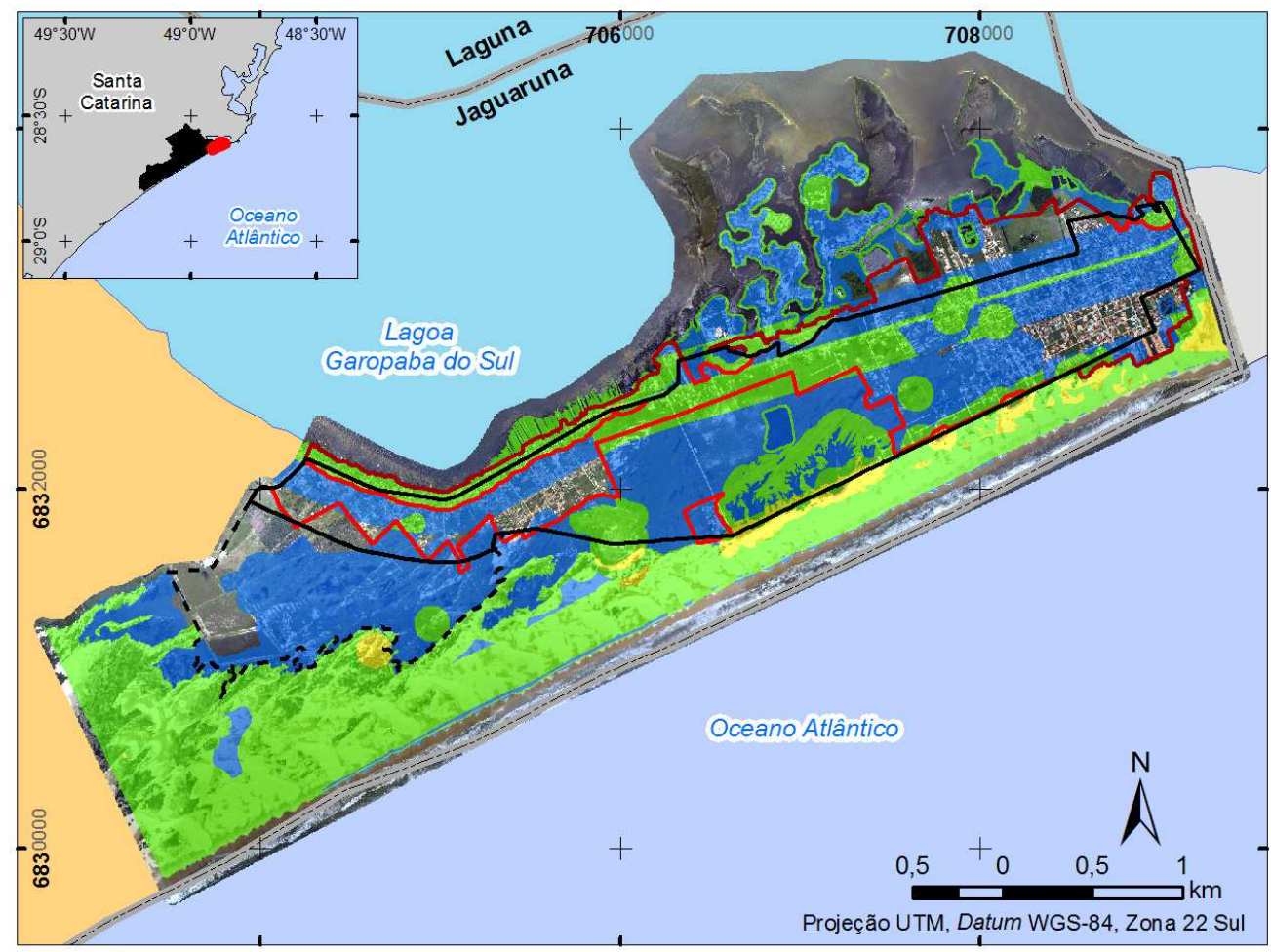

\section{Legenda}

\section{Macrozoneamento do Plano Diretor Municipal de Jaguaruna}

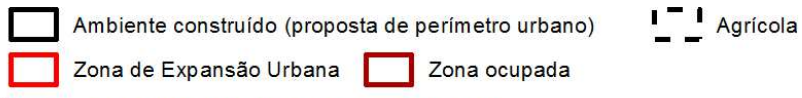

\section{Índice de Criticidade Legal-Ambiental}

Classes de criticidade

\begin{tabular}{|l|l|l}
\hline Inexistente & Baixo & Elevado \\
& Moderado & Complexo
\end{tabular}

FIGURA 3 - Índice de Criticidade Legal-Ambiental para a área de estudo.

FONTES: IBGE e Santa Catarina (2012b); elaboração própria. 
abrange $7,11 \mathrm{~km}^{2}$; se for considerado somente $10 \%$ do volume total da precipitação pluvial média na região (aproximadamente $140 \mathrm{~mm} /$ ano (Gruber et al., 2017a)), a filtragem d'água alcançaria 995.400.000 1/ano. Se como produto análogo utilizamos um filtro de barro com capacidade de filtragem de 7001 por vela, ao custo de R\$ 15 a vela, teremos como valor desse serviço a quantia de R \$ 21.330.000/ano;

- Provisão de hábitat: a forma mais simples de definir um hábitat é o local onde um organismo vive. Ao aplicar o valor per capita do IPTU arrecadado pelo município de Jaguaruna em 2014 (aproximadamente R\$ 140, segundo dados coletados pelo IBGE), a uma média de 2.000 lotes $/ \mathrm{km}^{2}$, obtemos que o valor desse geosserviço no ambiente natural $\left(9,06 \mathrm{~km}^{2}\right)$ equivale a R\$ 2.536.800/ano;

- Abastecimento de água potável: como mencionado anteriormente, os campos de dunas são filtradores e armazenadores naturais de água. Se for aproveitado somente 10\% da precipitação pluvial anual (995.400.000 1/ano) para abastecimento, segundo a tarifa média de água paga no Brasil em 2015 (R\$ 0,00296/1, segundo MC (2017)), o valor do geosserviço é igual a R\$ 2.946.384;

- Turismo e recreação: um desportista investe para praticar o surf, aproximadamente, $\mathrm{R} \$$ 3.000/ano para adquirir equipamentos e produtos de manutenção. Segundo DaCosta (2004), aproximadamente de $1,5 \%$ da população brasileira pratica o surf. Se esse percentual for aplicado aos 80.000 turistas que visitam o município de Jaguaruna no verão, obtemos que esse geosserviço cultural gratuito tem valor igual a R\$ 3.600.000/ano;
- Estético e de Inspiração: o turismo de sol e mar é um dos principais atrativos das regiões litorâneas e as razões disso são a satisfação pela admiração das belezas cênicas litorâneas e os efeitos psíquicos positivos de valores abstratos, como "estar em contato com a natureza”. É possível experimentar esse tipo de sentimento, de completude, ao frequentar o cinema. Se o preço médio de uma entrada de cinema é igual a R\$ 15 , ao utilizar os 80.000 turistas como base de cálculo para esse geosserviço, o montante alcançará o valor de R\$ 1.200.000/ano.

Os resultados obtidos indicam que os benefícios desses geosserviços gratuitos custariam aproximadamente R \$33.000.000/ano, 12\% do PIB municipal (em 3,8\% do território).

De posse desses dados e informações, foram elaboradas 135 planilhas com as ações de manejo concatenadas e de acordo com o tipo de cenário para cada condição de conflito, como mostra o exemplo na Tabela 7 .

A projeção espacial da consecução das ações e da localização de cada condição de conflito em mapas temáticos dos cenários de manejo possibilita a visualização e a definição de prioridades nas tomadas de decisões. O Cenário I (Figura 4) se constitui na conjuntura atual do PDM, em que se percebem algumas incoerências, como a definição do Sambaqui Garopaba do Sul como pertencente à Macrozona do Ambiente Construído e a desconsideração de parte do território municipal no macrozoneamento.

A projeção de tendência desse cenário é o aumento da ocorrência e da complexidade das condições de conflito devido à falta de clareza na fundamentação do macrozoneamento nos balneários. Nesse viés, as peculiaridades das dinâmicas 
TABELA 7 - Exemplo de avaliação de condição de conflito e proposição de ações de manejo (nesse caso, localizada na Macrozona Agrícola)

\begin{tabular}{|c|c|c|c|}
\hline $\begin{array}{r}\text { Região da diversida } \\
\text { Vegetação d }\end{array}$ & $\begin{array}{l}\text { mbiental } \\
\text { inga herbácea-subarbustiva com } 1\end{array}$ & gamento & \\
\hline Código do conflito & Tipologia & Área (m2) & Área total $(\%)$ \\
\hline 222 & Área, Pontual Difuso e Restrito & 31.332 & 3,18 \\
\hline
\end{tabular}

\section{Descrição do conflito/condicionante}

1 Risco de alagamento e/ou inundação

2 Densidade de conflitos $(100 \mathrm{~m})$

Complemento da descrição (quando pertinente)

1 Risco de alagamento

2 Depósito irregular de resíduos sólidos (também com disposição na forma de “aterro") e identificação de espécies exóticas

\section{Impactos}

Contaminação do solo/lençol freático

Poluição ambiental e proliferação de doenças

Ocupação e dispersão de espécies exóticas

\section{Ações de manejo - Cenário I (Manutenção da tendência atual de desenvolvimento)}

i Observar o disposto no Art. 179 da Lei Complementar Municipal nº 08/2014 (Código de Obras e Edificações)

ii Observar o Título III da Lei Complementar Municipal no 09/2014 (Código de Posturas)

iii Coleta de resíduos sólidos

iv Monitoramento e autuação

\section{Indicador(es) de controle}

i Registro de viabilidade a partir da última atualização de dados (em órgãos, autarquias, repartições públicas, etc.)

ii Registro de ocorrências de depósitos irregulares de resíduos sólidos

iii Escala de visitação e registro

\section{Efeitos}

a Proatividade legislativa e política do poder público

b Aumento de controle sobre a ação social no território

\section{Ações de manejo - Cenário II (Sustentabilidade como meta)}

... (i), (ii), (iii) e (iv)

v Levantamento/Atualização das condições legais/formais das propriedades/residências

vi Modificação do macrozoneamento - Sugestão: instituir a região como pertencente à Macrozona de Proteção Ambiental

\section{Indicador(es) de controle \\ ... (i), (ii), (iii) e (iv) \\ v Propriedades/Residências pelo total de registros cartoriais \\ vi Ato legislativo que formalize a alteração}

\section{Efeitos}

... (a) e (b)

c Aumento de receita (em potencial)

d Regularização fundiária/cartorial

\section{Ações de manejo - Cenário III (Reconstituição ambiental)}

... (i), (ii), (iii), (iv), (v) e (vi)

vii Controle sistemático de dispersão de espécies exóticas

\section{Indicador(es) de controle}

... (i), (ii), (iii), (iv), (v) e (vi)

vii Monitoramento e retirada de grupos de indivíduos florestais

\section{Efeitos}

$$
\text { ... (a), (b), (c) e (d) }
$$


e Diminuição da dispersão de espécies exóticas

f Salvaguarda de geosserviços de suporte (vários)

FONTE: elaboração própria.

NOTA: UHU, Uso Habitação Unifamiliar; UHMH, Uso Habitação Multifamiliar Horizontal; CSV, Comércio e Serviços Vicinais; CSB, Comércio e Serviços de Bairro; CSE, Comércio e Serviços Específicos; IBI, Industrial de Baixo Impacto; UI, Uso Institucional.

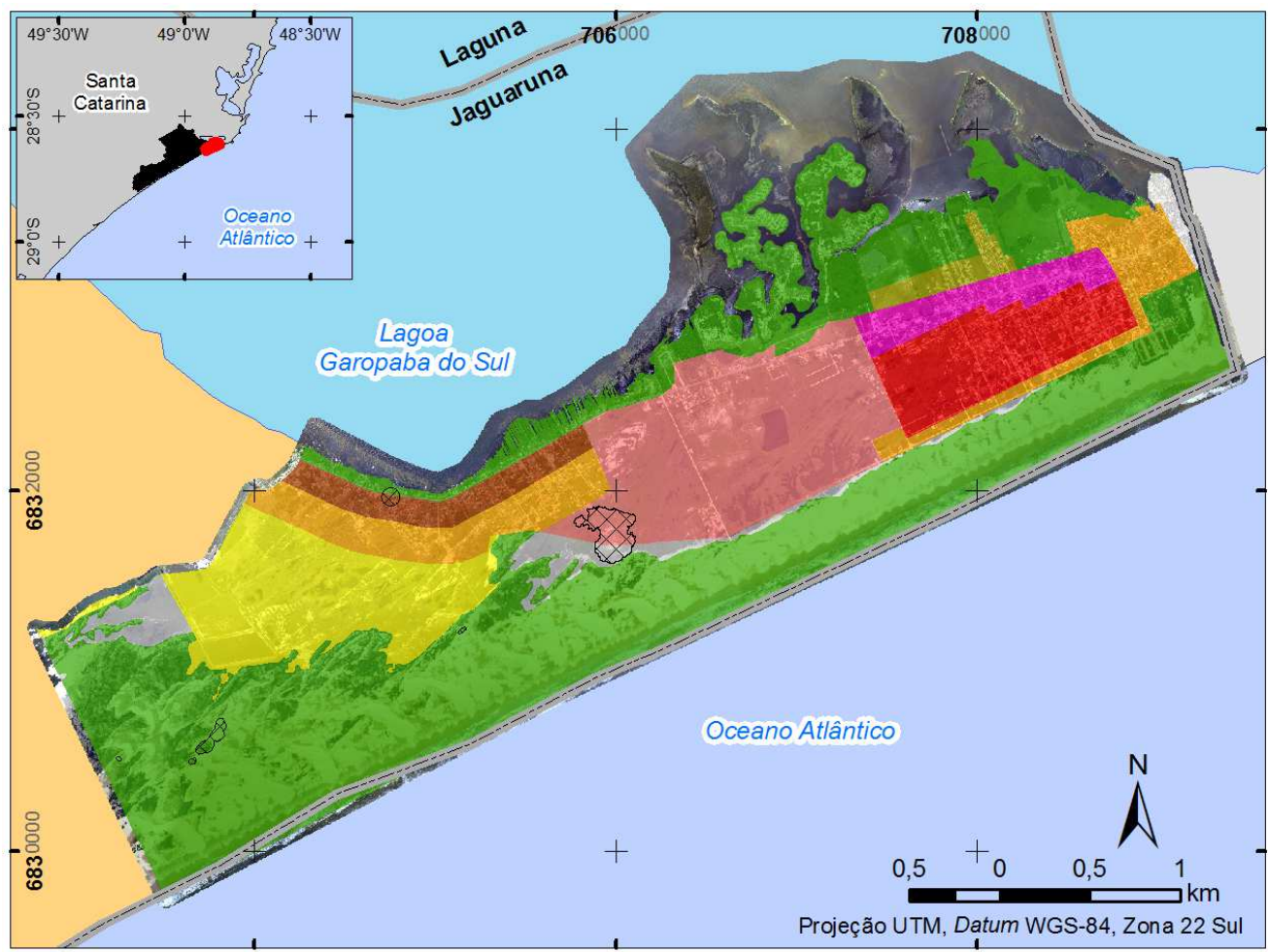

\section{Legenda}

XX Sambaquis

\section{Classes temáticas}

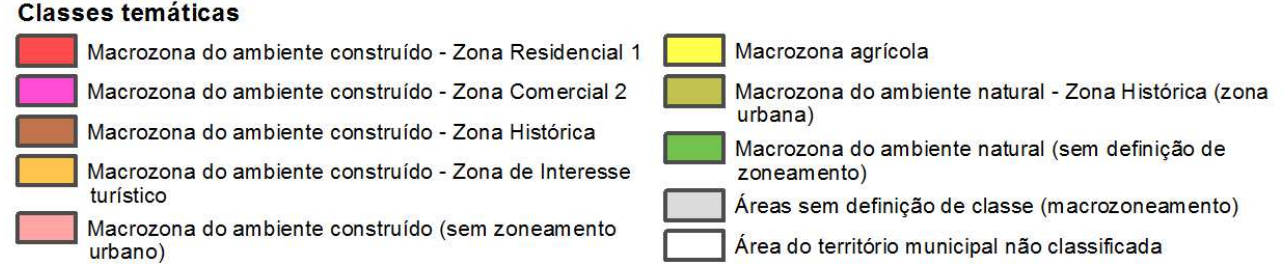

FIGURA 4 - Cenário de Manejo I.

FONTES: IBGE, Santa Catarina (2012a) e Jaguaruna (2014); elaboração própria. 
social e natural observadas na área de estudo (como a flutuação sazonal da população e o substrato poroso, por exemplo), aparentemente, não foram consideradas no macrozoneamento.

Nessa perspectiva, as principais ações de manejo buscam desacelerar a evolução de conflitos e a reversão de algumas condições de conflito crônicas pela observação de normativas existentes, pelo monitoramento e pela fiscalização de território, e pelas ações sociais por parte dos órgãos públicos municipais.

No Cenário II (Figura 5), as ações de manejo propostas buscam reorganizar o território a partir de dois enfoques: para o presente, readequação das condições urbanas e dos equipamentos urbanos a partir do levantamento e/ou da atualização de infor-

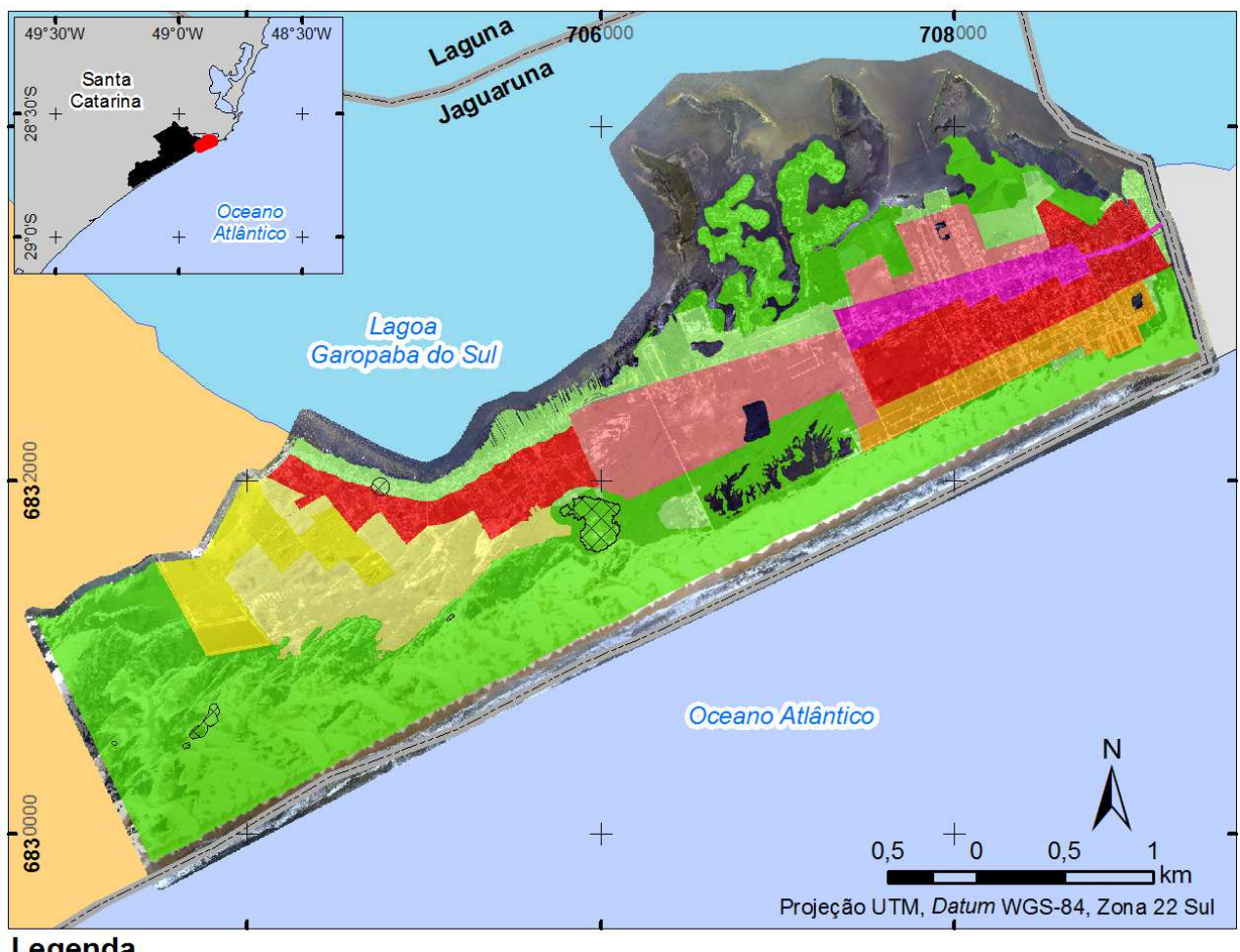

\section{Legenda}

X sambaquis

\section{Classes temáticas}

Macrozona de Ambiente Construído - Zona
de Interesse Turístico
MAC - Zona Residencial 1
MAC - Zona Residencial 2
MAC - Zona Comercial 2
Zona de Expansão Urbana

Macrozona Agrícola

MA - Zona de Transição

Macrozona de Proteção Ambiental - Zona de Proteção Limitada

MPA - Zona de Preservação Permanente

FIGURA 5 - Cenário de Manejo II.

FONTES: IBGE e Santa Catarina (2012b); elaboração própria. 
mações sociais; e para o futuro, direcionamento e controle da expansão urbana e da conservação ambiental a partir de alterações no macrozoneamento embasadas na dinâmica natural costeira.

Segundo esse cenário, espera-se o acréscimo de áreas naturais legalmente protegidas, tanto de per si como pela readequação do macrozoneamento baseada na designação de tipologias de zonas mais afins aos usos observados in loco. Em relação aos geosserviços, o prognóstico dos efeitos das ações acena para melhorias qualitativas e quantitativas de seus benefícios (pelo aumento de áreas protegidas e pela necessidade de recuperação ambiental); sobre os sambaquis, a implementação de estratégias de geoconservação intensifica a incorporação da conservação da natureza abiótica por meio da Educação Ambiental, da restrição/controle de acesso e da divulgação de sua relevância nos níveis nacional, estadual e municipal.

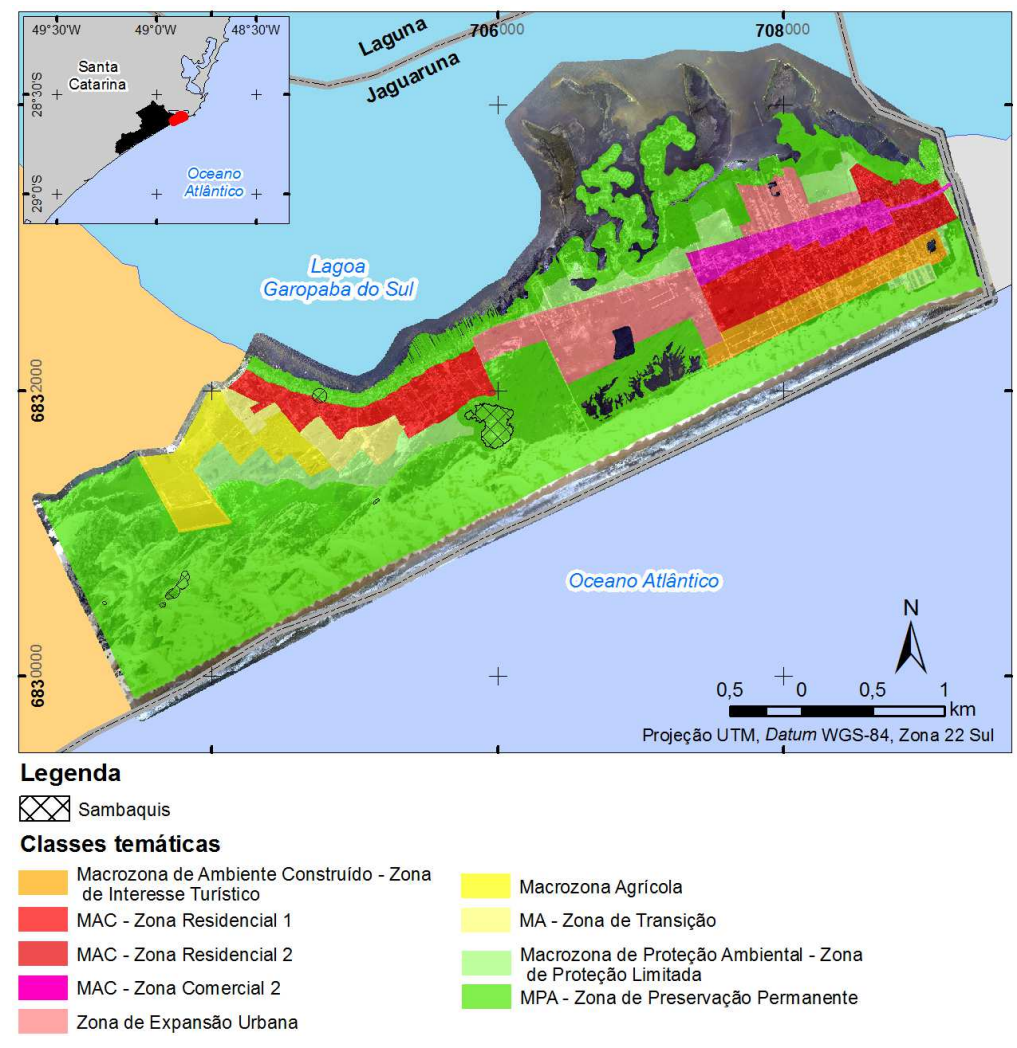

FIGURA 6 - Cenário de Manejo III.

FONTES: IBGE e Santa Catarina (2012b); elaboração própria. 
No Cenário III (Figura 6), é estimulada a reconstituição do ambiente natural por meio da salvaguarda e da reativação de dinâmicas ambientais originais. Muitas ações de manejo do cenário anterior encontram continuidade, e inclusive complementação, nesse cenário. O uso antrópico é reinterpretado e somente ocorre em áreas previamente ocupadas e/ou descaracterizadas, com a possibilidade de adensamento e/ou verticalização desde que os equipamentos urbanos e as condições de ocupação não alterem a dinâmica ambiental original.

As principais ações de manejo nesta perspectiva são:

- A remoção de residências e a proibição de ocupações em APPs e demais áreas de interesse ambiental;

- Recuperação ambiental de áreas degradadas;

- Transferência do "Direito de Construir" e reavaliação dos parâmetros urbanísticos;

- Estímulo a atividades denominadas "verdes", de baixo impacto e práticas de geoconservação, entre outras.

\section{Considerações finais}

Os cenários de manejo para a área de estudo destinam-se ao delineamento de novas estratégias de desenvolvimento, haja vista que o planejamento municipal para as áreas litorâneas não contemplava as suas peculiaridades. Entretanto, as tendências apresentadas têm caráter balizador, ou seja, não encerram todo o conjunto de alternativas possíveis e viáveis. Dessa forma, os gestores públicos podem deliberar um cenário híbrido para privilegiar algum resultado ou área específica.
As ações de manejo, por sua vez, se fundamentam na dinâmica entre as naturezas biótica e abiótica locais e visam à readequação das feições e das ações antrópicas para que sejam coerentes com o ambiente em que se localizam (em constante evolução geomorfológica e suscetível a desequilíbrios). Mas, assim como os cenários, as ações propostas não são as únicas capazes de equacionar as condições de conflito observadas; não obstante, por indicarem possibilidades de gestão do território embasadas em um enfoque holístico e integrado da Diversidade Ambiental, tais ações também têm a funcionalidade de garantir que futuras propostas também devam ser elaboradas com embasamento técnico e estar coerentes com as realidades ambiental e social.

Inovações relevantes da proposta de método de gerenciamento de condições de conflitos na zona costeira são a avaliação e a proposição de ações e de cenários de manejo fundamentados de forma primária sobre características da geodiversidade e da Diversidade Ambiental, o que resgata uma característica natural de todos os seres vivos de encontrar locais mais adequados para as suas atividades básicas (assentamento, deslocamento e fornecimento) a partir da compreensão das características abióticas.

Outro aspecto importante da proposta metodológica é que a avaliação não só incorpora e dá continuidade a outros instrumentos de gestão preexistentes, mas mantém os consensos coletivos deliberados em audiências públicas e em rodadas de debates sobre gestão de conflitos nos municípios costeiros, condição que atribui legitimidade à proposta e reforça os papéis de todos os atores envolvidos na promoção de ações que objetivem o equacionamento das condições de conflito, assim como a sua erradicação. 
Ademais, cabe ressaltar que: (a) a aplicação do ICLA proporcionou a identificação e a hierarquização de condições de conflito de forma simples e inteligível; e (b) as abordagens sobre os geosserviços e a Diversidade Ambiental possibilitaram a valoração de benefícios e das características da natureza abiótica para a comunidade local.

Os documentos que deram origem ao presente trabalho foram submetidos à avaliação do MPF, do Instituto do Meio Ambiente de Jaguaruna - IMAJ, da Secretaria de Estado de Planejamento de Santa Catarina, do GERCO/SC, da Fundação do Meio Ambiente do Estado de Santa Catarina (FATMA) e da APA da Baleia Franca tendo em vista a sua aplicação em TACs no município.

\section{Agradecimentos}

Ao Conselho Nacional de Desenvolvimento Científico e Tecnológico (CNPq) e à Coordenação de Aperfeiçoamento de Pessoal de Nível Superior (CAPES), pelas bolsas de estudo de Pós-Graduação, bolsas de iniciação científica de Graduação e demais fomentos de pesquisa; às Secretarias de Estado do Desenvolvimento Sustentável e do Planejamento de Santa Catarina, pelo aporte financeiro; ao Ministério Público Federal de Santa Catarina; ao Comitê Gestor Integrado do Programa Estadual de Gerenciamento Costeiro de Santa Catarina; ao Conselho Gestor da Área de Proteção Ambiental da Baleia Franca; à Fundação de Meio Ambiente do Estado de Santa Catarina; ao Município de Jaguaruna; à Associação dos Balneários de Jaguaruna, pelo apoio financeiro e logístico; aos colegas pesquisadores das Universidades Federais do Rio Grande do Sul e de Santa Catarina; aos revisores anônimos e editores da revista; e àqueles que a nossa memória possa ter olvidado, mas que sem o seu apoio nada disso seria possível.

\section{Referências}

Brasil. Decreto-Lei $n^{\circ}$ 9.760, de 5 de setembro de 1946. Dispõe sobre os bens imóveis da União e dá outras providências. Brasília/DF: DOU 06/09/1946. Disponível em: $<$ www.planalto.gov.br/ccivil_03/decreto-lei/del9760.htm>. Acesso em: 09 jul. 2013.

Brasil. Decreto $s / n^{\circ}$, de 14 de setembro de 2000. Cria a Área de Proteção Ambiental da Baleia Franca. Brasília/DF: DOU de 15/09/2000. Disponível em: <www.baleiafranca. org.br/area/decreto/decreto.htm>. Acesso em: 09 jul. 2013.

Brasil. Lei Federal $n^{\circ}$ 10.257, de 10 de julho de 2001. Regulamenta os artigos 182 e 183 da Constituição Federal, estabelece diretrizes gerais da política urbana e dá outras providências. Brasília/DF: DOU de 11/07/2001 (retificado em 17/07/2001). Disponível em: < www2.camara.leg.br/ legin/fed/lei/2001/lei-10257-10-julho-2001-327901-normaatualizada-pl.pdf $>$. Acesso em: 13 nov. 2014.

Brasil. Lei n ${ }^{\circ} 12.651$, de 25 de maio de 2012. Dispõe sobre a proteção da vegetação nativa e dá outras providências. Brasília/DF: DOU de 28/05/2012. Disponível em: <www. planalto.gov .br/ccivil_03/_Ato2011-2014/2012/Lei/ L12651 compilado.htm>. Acesso em: 04 jan. 2013.

CONAMA - Conselho Nacional do Meio Ambiente. Resolução $n^{\circ} 261$, de 30 de junho de 1999. Aprova parâmetro básico para análise dos estágios sucessivos de vegetação de restinga para o Estado de Santa Catarina. Brasília/DF: DOU de 30/06/1999. Disponível em: <www.mma.gov.br/ port/conama/legiabre.cfm?codlegi $=260>$. Acesso em: 13 nov. 2017.

CONAMA - Conselho Nacional do Meio Ambiente. Resolução $n^{\circ} 303$, de 20 de março de 2002. Dispõe sobre parâmetros, definições e limites de Áreas de Preservação Permanente. Brasília/DF: DOU de 13/05/2012. Disponível em: <www.mma.gov.br/port/conama//res/res02/res30302. html>. Acesso em: 13 nov. 2014. 
DaCosta, L. (Org.). Atlas do Esporte no Brasil. Brasília/ DF: ME, 2004. 858 p. Disponível em: <www.confef.org.br/ arquivos/atlas/atlas.pdf $>$. Acesso em: 28 jun. 2017.

Deblasis, P.; Kneip, A.; Scheel-Ybert, R.; Giannini, P. C.; Gaspar, M. D. Sambaquis e paisagem: dinâmica natural e arqueologia regional no litoral do sul do Brasil. Arqueologia Suramericana, 3(1), 29-61, 2007. Disponível em: $<$ www.museunacional.ufrj.br/arqueologia/docs/papers/rita/ RAS2007.pdf $>$. Acesso em: 28 jun. 2017.

EMBRAPA - Empresa Brasileira de Pesquisa Agropecuária. Centro Nacional de Pesquisa de Solos. Mapa de Solos do Estado de Santa Catarina. Boletim de Pesquisa, 6. Rio de Janeiro: EMBRAPA/CNPS, 1998. 4 cartas, color., $118 \mathrm{~cm}$ x $82 \mathrm{~cm}$, Escala 1:250:000.

Folha Regional (Org.). Moradores do Camacho são surpreendidos pela força da maré. Folha Regional Web TV News, 11/jun./2016. Santa Catarina, 2016. (3 min. e 30 seg.) Disponível em: $<$ https://youtu.be/CdHsFUC13x4>. Acesso em: 13 nov. 2017.

Gray, M. Geodiversity: valuing and conserving abiotic nature. 2. ed. Chichester/Inglaterra: Wiley-Blackwell, 2013.

Gruber, N. L. S.; Strohaecker, T. M.; Rockett, G. C.; Watanabe, T. P.; Bitencourt, V. J. B; Martins, E. M. Diagnóstico e Plano de Manejo das Dunas Frontais do Município de Jaguaruna: arcabouço teórico-conceitual. 2. ed. V. 1. Porto Alegre: UFRGS, 2017a.

Gruber, N. L. S.; Portz, L. C.; Cristiano, S. M.; Oliveira, R. M.; Oliveira, J. F.; Rockett, G. C.; Miranda, I. M.; Manzolli, R. P.; Martins, E. M. Diagnóstico e Plano de Manejo das Dunas Frontais do Município de Jaguaruna: orla marítima - morfodinâmica e aspectos ecológicos do sistema eólico-praial. 2. ed. V. 2. Porto Alegre: UFRGS, $2017 \mathrm{~b}$.

Gruber, N. L. S.; Barboza, E. G.; Martins, E. M.; Ferreira, B. F.; Watanabe, D. S. Z.; Vianna, N. Z. Diagnóstico e Plano de Manejo das Dunas Frontais do Município de Jaguaruna: Índice de Criticidade Legal - Ambiental. 2. ed. V. 3. Porto Alegre: UFRGS, 2017c.

Horn-Filho, N. O.; Felix, A.; Vieira, C. V.; Baptista, E. M. C.; Malandrin, D. A.; Leal, R. A.; Machado, V. C.; Silva, M. Mapa geológico da planície costeira das folhas Lagoa de Garopaba do Sul (SH-22-Z-XB-V-1) e Jaguaruna (SH-
22-X-B-IV-2), Santa Catarina, Brasil. In: Horn Filho, N.O. (Org.). Atlas geológico da planície costeira do Estado de Santa Catarina em base ao estudo dos depósitos quaternários. Série mapas IBGE, 9. Florianópolis: UFSC/CFH (Departamento de Geociências e Programa de Pós-Graduação em Geografia), CNPq; 2012. 1 carta, color., 84 cm x $59 \mathrm{~cm}$, Escala 1:100.000.

IBGE - Instituto Brasileiro de Geografia e Estatística. Levantamento aerofotogramétrico da Região Sul do Brasil: Folha SH.22-X-B-IV-2-SE. Rio de Janeiro, 2002a. 1 carta, color., $80 \mathrm{~cm}$ x $80 \mathrm{~cm}$, Escala 1:25.000. Disponível em: $<$ https://downloads.ibge.gov.br/downloads_geociencias. $\mathrm{htm}>$. Acesso em: 21 set. 2017 às $18 \mathrm{~h}$.

IBGE - Instituto Brasileiro de Geografia e Estatística. Levantamento aerofotogramétrico da Região Sul do Brasil: Folha SH.22-X-B-V-1-NE. Rio de Janeiro, 2002b. 1 carta, color., $80 \mathrm{~cm}$ x $80 \mathrm{~cm}$, Escala 1:25.000. Disponível em: $<$ https://downloads.ibge.gov.br/downloads_geociencias. htm>. Acesso em: 21 set. 2017 às $18 \mathrm{~h}$.

IBGE - Instituto Brasileiro de Geografia e Estatística. Levantamento aerofotogramétrico da Região Sul do Brasil: Folha SH.22-X-B-V-1-NO. Rio de Janeiro, 2002c. 1 carta, color., $80 \mathrm{~cm}$ x $80 \mathrm{~cm}$, Escala 1:25.000. Disponível em: $<$ https://downloads.ibge.gov.br/downloads_geociencias. $\mathrm{htm}>$. Acesso em: 21 set. 2017 às $18 \mathrm{~h}$.

IBGE - Instituto Brasileiro de Geografia e Estatística. Levantamento aerofotogramétrico da Região Sul do Brasil: Folha SH.22-X-B-V-1-SO. Rio de Janeiro, 2002d. 1 carta, color., $80 \mathrm{~cm} \mathrm{x} 80 \mathrm{~cm}$, Escala 1:25.000. Disponível em: $<$ https://downloads.ibge.gov.br/downloads_geociencias. $\mathrm{htm}>$. Acesso em: 21 set. 2017 às $18 \mathrm{~h}$.

Jaguaruna. Lei $n^{\circ} 1.385$, de 15 de dezembro de 2010. Altera a redação da Lei no 900/2001 que considera área de preservação permanente a área do sambaqui de Garopaba do Sul e dá outras providências. Jaguaruna: 2010. Disponível em: $<$ https://leismunicipais.com.br/plano-diretor-jaguaruna-sc $>$. Acesso em: 06 jan. 2017.

Jaguaruna. Lei Complementar $n^{\circ}$ 04, de 07 de janeiro de 2014. Dispõe sobre o Plano Diretor do Município de Jaguaruna e dá outras providências. Jaguaruna, 2014. Disponível em: $<$ https://leismunicipais.com.br/plano-diretor-jaguaruna-sc >. Acesso em: 06 jan. 2017. 
Martins, E. M.; Oliveira, J. F.; Bitencourt, V. J. B.; Scarelli, F. M.; Biancini-da-Silva, A.; Gruber, N. L. S.; Rosa, M. L. C. C.; Barboza, E. G. Comportamento Evolutivo da Barreira Costeira junto ao Balneário do Camacho, Jaguaruna/SC. Gravel, 12(1), 109-118. Porto Alegre: UFRGS, 2014. Disponível em: <www.ufrgs.br/gravel/12/1/Gravel_12_V1_04. pdf>. Último acesso em: 06 fev. 2017.

MC - Ministério das Cidades. Sistema Nacional de Informações sobre Saneamento: diagnóstico dos serviços de água e esgotos. Brasília/DF: SNSA/MCIDADES, 2017. Disponível em: <http:/wp.ufpel.edu.br/hugoguedes/files/2013/10/ Diagnostico_AE2015.pdf>. Acesso em: 28 jun. 2017.

MEA - Millenium Ecosystem Assessment. Ecosystems and human well-being: Framework of assessment. Washington/ EUA: Island Press, 2003. Disponível em: $<$ http://pdf.wri. org/ecosystems_human_wellbeing.pdf $>$. Acesso em: 20 ago. 2017.

Santa Catarina. Lei $n^{\circ}$ 6.063, de 24 de maio de 1982. Dispõe sobre o parcelamento do Solo Urbano e dá outras providências. Florianópolis: DOSC de 25/05/1982. Disponível em: $<$ www.deinfra.sc.gov.br/fxd/documentos/606382>. Acesso em: 28 ago. 2017.

Santa Catarina. Secretaria de Desenvolvimento Sustentável. Levantamento aerofotogramétrico do Estado de Santa Catarina: modelo numérico de superfície. Florianópolis: SDS, 2012a. Escala 1:10.000. Disponível em: <http://sigsc.sds. sc.gov.br/>. Acesso em: 02 fev. 2017.

Santa Catarina. Secretaria de Desenvolvimento Sustentável. Levantamento aerofotogramétrico do Estado de Santa Catarina: mosaico de fotografias aéreas ortorretificadas. Florianópolis: SDS, 2012b. Escala 1:10.000. Disponível em: <http://sigsc.sds.sc.gov.br/>. Acesso em: 02 fev. 2017.

Santa Catarina. Secretaria de Planejamento. Roteiro Metodológico: abordagem para análises e construção de termos de ajuste de conduta, visando ao gerenciamento de conflitos de ocupação nos municípios do Litoral Sul de Santa Catarina. Florianópolis: SPG, 2015. 36 p.

Santa Catarina. Secretaria do Planejamento. Diretoria de Estatística e Cartografia. Levantamento aerofotogramétrico parcial do Estado de Santa Catarina. Florianópolis: SPG/ DEGE, 1978. 3 fotografias aéreas digitais, $P \& B, 23 \mathrm{~cm} \mathrm{x}$
$23 \mathrm{~cm}$, Escala 1:25.000.

Santa Catarina. Secretaria do Planejamento. Diretoria de Estatística e Cartografia. Levantamento aerofotogramétrico parcial do Estado de Santa Catarina. Florianópolis: SPG/ DEGE, 1957. 3 fotografias aéreas digitais, $P \& B, 23 \mathrm{~cm} \mathrm{x}$ $23 \mathrm{~cm}$, Escala 1:25.000.

Santa Catarina. Secretaria do Planejamento. Diretoria de Estatística e Cartografia. Levantamento aerofotogramétrico parcial do Estado de Santa Catarina. Florianópolis: SPG/ DEGE, 1938. 3 fotografias aéreas digitais, $P \& B, 23 \mathrm{~cm} \mathrm{x}$ $23 \mathrm{~cm}$, Escala 1:30.000.

Sharples, C. Concepts and principles of geoconservation. 3. ed. Tasmânia: Tasmanian Parks \& Wildlife Service, 2002. 81 p. Disponível em: $<$ http://dpipwe.tas.gov.au/Documents/ geoconservation.pdf $>$. Acesso em: 20/08/2017.

Vieira, J. Força da maré surpreende moradores. Notisul, 13/ jun./2016. Santa Catarina, 2016. Disponível em: <www. notisul.com.br/n/ultimas/forca_da_mare_surpreende_moradores-57964>. Acesso em: $2 \overline{6}$ jan. $201 \overline{7}$. 